BMJ Open

Diabetes

Research

\& Care

\section{Correlates of cardiorespiratory fitness among overweight or obese individuals with type 2 diabetes}

To cite: Kaze AD, Agoons DD, Santhanam P, et al. Correlates of cardiorespiratory fitness among overweight or obese individuals with type 2 diabetes. BMJ Open Diab Res Care 2022;10:e002446. doi:10.1136/ bmjdrc-2021-002446

Received 18 June 2021 Accepted 17 October 2021

Check for updates

(c) Author(s) (or their employer(s)) 2022. Re-use permitted under CC BY-NC. No commercial re-use. See rights and permissions. Published by BMJ.

${ }^{1}$ Department of Medicine, University of Maryland School of Medicine, Baltimore, Maryland, USA

${ }^{2}$ Department of Medicine, UPMC Pinnacle, Harrisburg, Pennsylvania, USA

${ }^{3}$ Department of Medicine, Johns Hopkins University School of Medicine, Baltimore, Maryland, USA

${ }^{4}$ Department of Medicine, Brown University Warren Alpert Medical School, Providence, Rhode Island, USA

Correspondence to Dr Justin B Echouffo-Tcheugui; jechouf1@jhmi.edu

\section{ABSTRACT}

Introduction Mechanistic studies suggest that type 2 diabetes is independently associated with low cardiorespiratory fitness (CRF). Little is known about the CRF profile in type 2 diabetes; we assessed the correlates of low CRF among overweight/obese adults with type 2 diabetes.

Research design and methods A total of 4215 participants with type 2 diabetes and without cardiovascular disease underwent maximal exercise testing in the Look AHEAD (Action for Health in Diabetes) study. Low CRF was defined based on the Aerobics Center Longitudinal Study reference standards. Calorie intake and physical activity were assessed using questionnaires. Body fat composition was assessed using dual-energy X-ray absorptiometry.

Results Waist circumference, systolic blood pressure, glycemic measures, whole body fat, caloric intake, and fatfree mass were inversely associated with fitness across sex (all $p<0.001$ ). Comparing with moderate or high CRF groups, the low CRF group was associated with higher adjusted odds of obesity (OR 3.19 (95\% Cl 1.95 to 5.20$)$ in men, 3.86 (95\% Cl 2.55 to 5.84$)$ ) in women), abdominal obesity (OR 3.99 (95\% Cl 2.00 to 7.96$)$ in men, 2.28 (95\% $\mathrm{Cl} 1.08$ to 4.79 ) in women), hypertension (OR 1.74 (95\% Cl 1.09 to 2.77$)$ in men, $1.44(95 \% \mathrm{Cl} 1.02$ to 2.05$)$ in women), metabolic syndrome (OR $5.52(95 \% \mathrm{Cl} 2.51$ to 12.14) in men, 2.25 (95\% Cl 1.35 to 3.76) in women), use of beta-blocker (1.22 (95\% $\mathrm{Cl} 0.86$ to 1.73$)$ in men, 1.33 (95\% Cl 1.03 to 1.73 ) in women), and ACE inhibitor/ angiotensin-receptor blocker ( $1.86(95 \% \mathrm{Cl} 1.39$ to 2.50$)$ in men, 1.07 (95\% Cl 0.86 to 1.32) in women). Women with low CRF had higher odds of current smoking $(2.02(95 \% \mathrm{Cl}$ 1.25 to 3.28$)$ ).

Conclusions Low CRF was associated with increased odds of cardiometabolic correlates in a large cohort of adults with type 2 diabetes.

\section{INTRODUCTION}

Cardiorespiratory fitness (CRF) represents the ability of the body to carry oxygen from the atmosphere to the mitochondria and the ability of the cell to use that oxygen in order to perform physical activity. ${ }^{1-3}$ CRF appraises the functional capacity of an individual, and is directly linked to the integrated function of several body systems and is therefore

\section{Significance of this study}

What is already known about this subject?

- Mechanistic studies suggest that obesity and type 2 diabetes may be independently associated with low cardiorespiratory fitness (CRF).

- Low CRF may be a strong predictor of mortality and cardiovascular disease in type 2 diabetes.

- Little is known about the CRF profile among overweight and obese adults with type 2 diabetes in the USA.

What are the new findings?

- Waist circumference, systolic blood pressure, glycemic measures, whole body fat, caloric intake, and fat-free mass are inversely associated with fitness across sex categories.

- Low CRF is linked with higher adjusted odds of obesity, hypertension, metabolic syndrome, and current smoking.

How might these results change the focus of research or clinical practice?

- Additional research is needed to further elucidate the mechanisms leading to alterations in fitness levels among overweight and obese individuals with type 2 diabetes, especially given the rising burden of obesity in the USA.

considered a marker of total body health. ${ }^{1-3}$ There is evidence that low CRF may be a strong predictor of mortality. ${ }^{14-6}$ However, it is currently not routinely assessed in clinical settings, nor included in cardiovascular disease (CVD) risk calculators for the general population and for those with diabetes in particular. Indeed, the rates of diabetes have remained high in the USA, paralleling those of physical inactivity and obesity. ${ }^{7-9}$ CRF may be particularly important for risk stratification among individuals with type 2 diabetes. Indeed, mechanistic studies suggested that type 2 diabetes is associated with alterations in CRF even in the absence of CVD. ${ }^{10-17}$ However, population-based studies of CRF in people with type 2 diabetes (especially those 
free of CVD) are lacking. A better characterization of the CRF profile in this population may offer potential insights into pathways leading to CVD, as well as inform strategies to curb the high burden of CVD in this highrisk population.

We investigated the clinical correlates of low CRF among adults with type 2 diabetes in a community-based sample, using data from the Look AHEAD (Action for Health in Diabetes) study.

\section{METHODS}

Study design

The details about the Look AHEAD study have been published elsewhere. ${ }^{18}$ Briefly, the Look AHEAD study was a US-based multicenter randomized, double-blind clinical trial designed to investigate the effects of intensive lifestyle interventions (achieved through healthy eating and increased physical activity) compared with the then 'standard of care' diabetes management on cardiovascular outcomes. A total of 5145 participants were enrolled and randomly assigned to an intensive lifestyle intervention (intervention group) or to diabetes support and education (control group). The participants met the following criteria: age 45 to 76 years; self-reported diagnosis of type 2 diabetes verified by measured glucose levels, use of antidiabetic medication or medical records; body mass index (BMI) $\geq 25 \mathrm{~kg} / \mathrm{m}^{2}$ ( $\geq$ or $27 \mathrm{~kg}$ / $\mathrm{m}^{2}$ in patients taking insulin); glycosylated hemoglobin $\left(\mathrm{HbA}_{1 \mathrm{C}}\right) \leq 11 \%$; systolic blood pressure (BP) $<160 \mathrm{mmHg}$; diastolic $\mathrm{BP}<100 \mathrm{mmHg}$; triglyceride levels $<600 \mathrm{mg} / \mathrm{dL}$; the ability to complete a valid maximal exercise test, indicating that it was safe to exercise; an established relationship with a primary provider. ${ }^{18}$

We only included patients who attended the baseline examination. Among these patients, we excluded those with consent restrictions $(n=244)$ and those with prevalent CVD at baseline ( $\mathrm{n}=691)$. After these exclusions, 4215 participants were included in our main analyses.

\section{Cardiorespiratory fitness estimation}

CRF was estimated using a graded maximal exercise treadmill test as described previously. ${ }^{19} \mathrm{CRF}$ was defined as the estimated metabolic equivalent of task (MET) based on the treadmill work load (ie, speed and grade), where 1 MET is equal to $3.5 \mathrm{~mL} / \mathrm{kg} / \mathrm{min}$ of oxygen uptake. ${ }^{19} \mathrm{~A}$ 12-lead ECG and BP were recorded at rest, during exercise, and during recovery. After an appropriate warm-up, participants exercised to the point of volitional exhaustion or until specific criteria to terminate the test were observed. ${ }^{19} 20$ The test was considered valid if the participant reached at least $85 \%$ of age-predicted maximal heart rate $\left(\mathrm{HR}_{\mathrm{MAX}}=220\right.$-age $)$ if not taking a beta-blocking agent. If the participant was taking a beta blocker, the test was considered valid if the Borg Rating of Perceived Exertion met or exceeded 18 at the point of termination. ${ }^{19}$ Only participants who achieved at least 4 METs were eligible for participation in the Look AHEAD study. ${ }^{19}$
Sex-specific distributions of METs were formed within the following age groups: 40-49, 50-59, 60-69, and 70-79 years. ${ }^{52021}$ Each age-specific and sex-specific distribution was divided into quintiles. Fitness was further categorized as low ( $<20$ th percentile), moderate $(20$ th -59 th percentiles), and high ( $>60$ th percentile) based on published data from the Aerobics Center Longitudinal Study. ${ }^{5} 2021$

\section{Assessment of calorie intake and physical activity}

Calorie intake was assessed using a previously validated food frequency questionnaire (FFQ) among $50 \%$ of Look AHEAD participants $(n=2305) .{ }^{22}$ This questionnaire was a modified version of the Diabetes Prevention Program FFQ designed to gather data on usual intake of food items over the preceding 6 months. ${ }^{22}$ Physical activity was measured in a subset of participants $(n=2402)$ using the Paffenbarger Activity Questionnaire which estimates weekly energy expenditure from moderate-intensity physical activity. ${ }^{23}$

\section{Assessment of body fat composition}

Body composition was assessed by dual-energy X-ray absorptiometry (DEXA) in a subset of participants $(\mathrm{n}=1186)$ at four Look AHEAD centers using Hologic (QDR-4500A) fan beam densitometers. ${ }^{24}$ Lean mass (LM) was calculated as the difference between fat-free mass and bone mineral content. Precision for fat mass (FM) is $1.5 \%$ in lean and obese subjects. Precision for LM is $0.45 \%$ in lean participants and $0.80 \%$ among obese subjects. ${ }^{24}{ }^{25}$ Hologic software was used to correct for underestimation of FM. ${ }^{24} 26$

\section{Assessment of other covariates}

Data on age, sex, race/ethnicity, duration of diabetes, history of CVD, medication use, current smoking, and alcohol use were obtained from each participant using standardized questionnaires. ${ }^{18}$ Weight and height were measured twice using a digital scale and a standard stadiometer, respectively; the average of those duplicate readings were used for the analyses. ${ }^{18}$ BMI was computed as weight in kilograms divided by square of height in meters. Waist circumference was measured with participants in light clothing using a non-metallic, constant tension tape placed around the body at midlevel between the highest point of the iliac crest and lowest point of the costal margin on the mid-axillary line. BP was measured in duplicate with participants seated, and the average of the two readings was used in the analyses. Participants provided venous blood samples after at least 8 hours of fasting. Blood samples were stored at less than $-20^{\circ} \mathrm{C}$ and shipped to the look AHEAD Central Biochemistry Laboratory (Northwest Lipid Metabolism and Diabetes Research Laboratories, University of Washington, Seattle, WA) where assays were performed. $\mathrm{HbA}_{1 \mathrm{C}}$ was measured by a dedicated ion exchange high-performance liquid chromatography instrument (Biorad Variant II). Fasting plasma glucose (FPG) was measured using the glucokinase method and oxidase method. ${ }^{18}$ Plasma total 
cholesterol and triglyceride were measured enzymatically using methods standardized to the Centers for Disease Control and Prevention reference methods. High-density lipoprotein cholesterol (HDL-C) was assayed by the treatment of whole plasma with dextran sulfate- $\mathrm{Mg}^{2+}$ to precipitate all of the apolipoprotein B-containing lipoproteins. The Friedewald equation was used to calculate low-density lipoprotein cholesterol (LDL-C) concentrations. ${ }^{27}$

Overweight was defined as BMI of $25 \mathrm{~kg} / \mathrm{m}^{2}$ or greater and less than $30 \mathrm{~kg} / \mathrm{m}^{2}$; obesity as BMI of $30 \mathrm{~kg} / \mathrm{m}^{2}$ or greater, ${ }^{28}$ hypertension as $\mathrm{BP} \geq 130 / 80 \mathrm{~mm} \mathrm{Hg}$ or use of antihypertensive medication; ${ }^{29}$ hypercholesterolemia as low-density lipoprotein cholesterol $\geq 130 \mathrm{mg} / \mathrm{dL}$ or use of cholesterol-lowering medication. The metabolic syndrome was defined based on the National Cholesterol Education Program's Adult Treatment Panel III (NCEP ATP III) criteria,${ }^{30}$ as the presence of three or more of the following: (1) abdominal obesity (waist circumference (WC) $\geq 102 \mathrm{~cm}$ for men or $\geq 88 \mathrm{~cm}$ for women); (2) triglyceride level $\geq 150 \mathrm{mg} / \mathrm{dL}$; (3) HDL cholesterol $<40 \mathrm{mg} / \mathrm{dL}$ for men or $<50 \mathrm{mg} / \mathrm{dL}$ for women; (4) impaired glucose tolerance (fasting glucose $\geq 100 \mathrm{mg}$ / $\mathrm{dL}$ or $\mathrm{HbA}_{1 \mathrm{C}} \geq 5.7 \%$ ); (5) $\mathrm{BP} \geq 130 / 85 \mathrm{~mm} \mathrm{Hg}$. All the participants met the fourth criteria as they all had type 2 diabetes.

\section{Statistical analysis}

All analyses were stratified by sex (as CRF is known to vary with sex).$^{31}$ Participant characteristics were described using means $(\mathrm{SD})$ or proportions. To evaluate the association between fitness and CVD risk factors, we categorized estimated METs into age-specific and sex-specific deciles and plotted the age-adjusted and race-adjusted means of each CVD risk factor by sex. Next, we calculated age-adjusted and race-adjusted means and 95\% CIs of continuous covariates by categories of fitness and sex, comparing the low and moderate fitness groups with the high-fitness category using $\mathrm{F}$ tests. Logistic regression models were used to calculate ORs and associated 95\% CIs for categorical covariates, comparing participants with low fitness with those in the moderate-fitness or high-fitness categories. All logistic regression models included age, race, BMI, total-to-HDL cholesterol ratio, $\mathrm{HbA}_{1 \mathrm{C}}$, alcohol drinking, current smoking, and HTN; except total-to-HDL cholesterol ratio for the hypercholesterolemia and low-HDL cholesterol outcomes; BMI, $\mathrm{HbA}_{1 \mathrm{C}}$, and HTN for the metabolic syndrome outcome; HTN for beta-blocker use or ACEI/ARB use outcomes; and BMI for the obesity or abdominal obesity outcomes.

A two-sided $p$ value of $<0.05$ was considered statistically significant for all analyses. All analyses were performed using STATA 14.2 (Stata Inc., College Station, TX).

\section{RESULTS}

The study sample consisted of 4215 participants (mean age: 58.4 (SD 6.6) years, $61.9 \%$ women). Table 1 displays the sex-specific characteristics of participants.

\section{Low cardiorespiratory fitness by sex and race/ethnicity}

As expected, the prevalence rates of low, moderate, and high fitness were $21.1 \%$ (95\% CI 19.9 to 22.3 ), $38.2 \%$ (36.3 to 40.0 ), and $39.5 \%$ (37.7 to 41.4) for women; and $19.0 \%$ (17.2 to 21.0 ), $40.0 \%$ (37.6 to 42.4 ), and $40.9 \%$ (38.6 to 43.4) for men. Figure 1 displays the prevalence of low fitness by race/ethnicity. Among men, low fitness was more prevalent across age in Black participants, whereas among women, low fitness was more frequent in Blacks followed by White participants.

\section{Fitness and cardiometabolic traits}

Figure 2 shows the association between deciles of fitness (METs) and selected covariates across sex. Anthropometric measures (BMI and $\mathrm{WC}$ ), as well as $\mathrm{SBP}$ and $\mathrm{HbA}_{1 \mathrm{C}}$ demonstrated a graded inverse association with fitness.

Table 2 displays age-adjusted and race-adjusted means of selected correlates by fitness status categorized into three groups. Men and women with low fitness had significantly higher mean BMI, WC, SBP, FPG, $\mathrm{HbA}_{1 \mathrm{C}}$, and duration of diabetes (table 2). Men with low fitness had significantly higher triglyceride and lower HDLcholesterol levels. No significant difference in DBP, total cholesterol, or LDL cholesterol was observed across fitness categories (table 2).

Table 3 shows age-adjusted and race-adjusted odds of CVD risk factors among participants with low fitness status (compared with high fitness) stratified by sex. In men and women, those with low fitness were more likely to have abdominal obesity (3.99 (95\% CI 2.00 to 7.96 ) for men and 2.28 (95\% CI 1.08 to 4.79) for women), hypertension (OR 1.74 (95\% CI 1.09 to 2.77) for men and 1.44 (95\% CI 1.02 to 2.05) for women), metabolic syndrome (OR 5.52 (95\% CI 2.51 to 12.14) for men and 2.25 (95\% CI 1.35 to 3.76 ) for women), current smoking, use beta blockers (OR 1.22 (95\% CI 0.86 to 1.73$)$ for men and 1.33 (95\% CI 1.03 to 1.73) for women), and use of ACE inhibitors (ACEI) or angiotensin receptor blockers (ARB) (OR 1.86 (95\% CI 1.39 to 2.50) for men and 1.07 (95\% CI 0.86 to 1.32 ) for women).

\section{Fitness, caloric intake, and physical activity}

A subset of participants had data collected on caloric intake $(n=2305)$ and physical activity $(n=2402)$. As shown in table 2, women in the low fitness group had significantly higher adjusted mean of calorie intake compared with those in the moderate or high fitness groups, whereas no significant difference in mean calorie intake was noted among men. Men and women in the low fitness category had significantly lower adjusted mean of physical activity levels as compared with higher fitness categories (table 2).

\section{Fitness and body fat composition}

Body composition was assessed among 1186 participants. The adjusted means of whole-body fat, fat-free mass, lean mass, and whole-body mass were significantly higher in the low fitness group (as compared with higher fitness 
Table 1 Characteristics of participants without cardiovascular disease at baseline in the Look AHEAD study

\begin{tabular}{|c|c|c|}
\hline & Women & Men \\
\hline Size, $n(\%)$ & $2613(62.0)$ & $1602(38.0)$ \\
\hline \multicolumn{3}{|l|}{ Treatment assignment, $\mathrm{n}(\%)$} \\
\hline Diabetes support and education & $1316(50.4)$ & $804(50.2)$ \\
\hline Intensive lifestyle intervention & $1297(49.6)$ & $798(49.8)$ \\
\hline Age, years & $57.8(6.6)$ & $59.3(6.6)$ \\
\hline \multicolumn{3}{|l|}{ Race/ethnicity, n (\%) } \\
\hline White & $1512(57.9)$ & $1224(76.4)$ \\
\hline Non-Hispanic Black & $561(21.5)$ & $164(10.2)$ \\
\hline Hispanic & $443(17.0)$ & $167(10.4)$ \\
\hline Other/mixed & $97(3.7)$ & $47(2.9)$ \\
\hline Current smoking, $\mathrm{n}(\%)$ & $105(4.0)$ & $65(4.1)$ \\
\hline Alcohol drinking, n (\%) & $588(22.5)$ & $786(49.1)$ \\
\hline Calorie intake, ${ }^{*} \mathrm{kcal} /$ day & $1880.4(826.7)$ & $2180.9(917.1)$ \\
\hline Physical activity,§ kcal/week & $392.0(112.0-952.0)$ & $672.0(196.0-1484.0)$ \\
\hline Weight, kg & $95.5(17.6)$ & $109.5(18.8)$ \\
\hline Body mass index, $\mathrm{kg} / \mathrm{m}^{2}$ & $36.5(6.1)$ & $35.2(5.6)$ \\
\hline Waist circumference, $\mathrm{cm}$ & $110.7(13.4)$ & $118.5(13.7)$ \\
\hline Systolic blood pressure, $\mathrm{mm} \mathrm{Hg}$ & $129.2(17.2)$ & $129.1(16.3)$ \\
\hline Diastolic blood pressure, $\mathrm{mm} \mathrm{Hg}$ & $68.3(9.2)$ & $73.9(8.9)$ \\
\hline Hypertension, ๆ n (\%) & $2242(85.8)$ & $1371(85.6)$ \\
\hline Obesity, n (\%) & $2256(86.3)$ & $1342(83.8)$ \\
\hline Abdominal obesity, $\mathrm{n}(\%)$ & $2534(97.0)$ & $1441(90.0)$ \\
\hline Use of antihypertensive medication, $\mathrm{n}(\%)$ & $1878(71.8)$ & $1123(70.1)$ \\
\hline Use of beta blocker, n (\%) & $452(17.3)$ & $274(17.10)$ \\
\hline Use of ACEI or ARB, $n(\%)$ & $1445(55.3)$ & $910(56.8)$ \\
\hline Fasting plasma glucose, mg/dL & $150.9(44.7)$ & $155.6(47.2)$ \\
\hline Hemoglobin $\mathrm{A}_{1 \mathrm{C}}, \%$ & $7.3(1.1)$ & $7.2(1.2)$ \\
\hline Duration of diabetes, years & $5.0(2.0-9.0)$ & $5.0(2.0-10.0)$ \\
\hline Triglyceride, mg/dL & $147.0(105.0-210.0)$ & $160.0(110.0-232.0)$ \\
\hline Total cholesterol, mg/dL & $198.3(36.4)$ & $184.4(36.0)$ \\
\hline High-density lipoprotein cholesterol, mg/dL & $47.3(12.1)$ & $38.3(9.3)$ \\
\hline Low-density lipoprotein cholesterol, mg/dL & $117.3(32.5)$ & $109.2(30.6)$ \\
\hline Hypercholesterolemia, ${ }^{\star \star}$ n (\%) & $1754(67.1)$ & $1100(68.7)$ \\
\hline Metabolic syndrome, $†$ n (\%) & $2464(94.3)$ & $1454(90.8)$ \\
\hline Maximal MET value & $6.7(1.7)$ & $8.1(2.1)$ \\
\hline \multicolumn{3}{|l|}{ Body composition variablesł } \\
\hline Whole body fat, $\mathrm{kg}$ & $39.8(10.4)$ & $32.7(9.1)$ \\
\hline Whole body fat-free mass, $\mathrm{kg}$ & $53.0(7.0)$ & $71.1(7.6)$ \\
\hline Whole body lean mass, $\mathrm{kg}$ & $50.8(6.8)$ & $68.3(7.3)$ \\
\hline Whole body mass, kg & $92.8(16.0)$ & $103.7(14.2)$ \\
\hline Percent body fat, \% & $42.4(4.7)$ & $31.0(5.2)$ \\
\hline
\end{tabular}

Data are mean (SD), median (IQR), or number (\%) unless otherwise indicated.

${ }^{*}$ Calorie intake data were available for 2305 participants ( 1415 women and 890 men) who completed the food frequency questionnaire. Abdominal obesity was defined as waist circumference $\geq 102 \mathrm{~cm}$ for men or $\geq 88 \mathrm{~cm}$ for women. Obesity was defined as BMl of $30 \mathrm{~kg} / \mathrm{m}^{2}$ or greater.

†The metabolic syndrome was defined based on the National Cholesterol Education Program Adult Treatment Panel III guidelines.

łBody composition data were available for 1186 participants (772 women and 414 men) who had completed the DEXA scan.

§Physical activity data were available for 2402 participants (1226 women and 806 men) who completed the Paffenbarger Activity Questionnaire.

ๆHypertension was defined as BP $\geq 130 / 80 \mathrm{~mm} \mathrm{Hg}$ or use of antihypertensive medication.

${ }^{* *}$ Hypercholesterolemia was defined as low-density lipoprotein cholesterol $\geq 130 \mathrm{mg} / \mathrm{dL}$ or use of cholesterol-lowering medication.

ACEI, ACE inhibitor; AHEAD, Action for Health in Diabetes; ARB, angiotensin II receptor blocker; DEXA, dual-energy X-ray absorptiometry; MET, metabolic equivalent. 


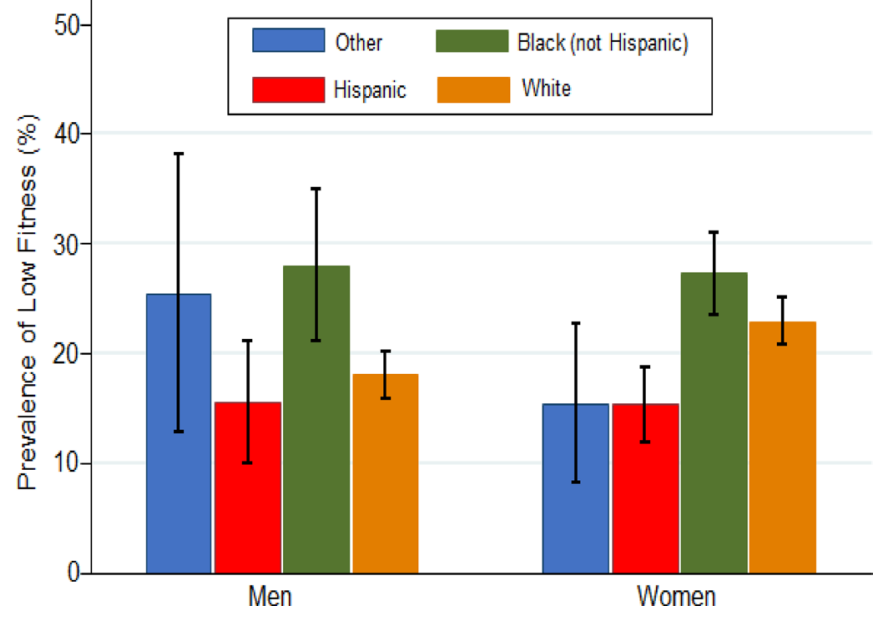

Figure 1 Low cardiorespiratory fitness by sex and race/ ethnicity among overweight/obese adults with type 2 diabetes. The Look AHEAD (Action for Health in Diabetes) study. Error bars indicate $95 \% \mathrm{Cl}$.

ranges) among men and women (table 2). Moreover, total body fat displayed a graded inverse association with deciles of fitness among men and women (figure 2).

\section{DISCUSSION}

In this study, we described the correlates of CRF in a community-based sample of adults with type 2 diabetes. We made several observations. There is a strong and inverse association between low fitness and several cardiometabolic factors, including obesity (overall and abdominal), hypertension, and metabolic syndrome and the use of cardioprotective medications. In addition, lower fitness was associated with higher calorie intake among women, and with lower physical activity levels as well as higher whole-body fat and fat-free mass across sex.

Our study is unique in several ways, which include the assessment of the contribution to fitness of caloric intake, body fat composition assessed via DEXA, as well as the use of cardioprotective medications (beta blockers and ACEI/ARB). Our study complements prior reports based on the Look AHEAD data, which assessed fitness as a continuous outcome, and did not evaluate the specific relations of fitness with physical activity, caloric intake, DEXA-based fat and lean mass indices, as well as the use of ACEI/ARB. ${ }^{32} 33$ In a previous report of a representative sample of the US population, the prevalence of low fitness among US adults was $13.9 \%,{ }^{34}$ although their focus was not on individuals with diabetes, and more importantly CRF was estimated using a submaximal treadmill testing which is inferior to symptom-limited maximal testing due to its reliance on prediction formulas, and may not apply to women, increasing the chance of measurement errors. ${ }^{20}$ In our study, participants were referred by their primary care physician to participate in a clinical trial and are likely to be healthier than their counterparts with diabetes in the general population. ${ }^{35}$ Our findings on the associations of lower CRF with higher odds of major CVD risk factors (including glycemic markers, blood pressure, obesity) are consistent with prior reports made in the general population, although none of previous studies exclusively focused on individuals with type 2 diabetes. ${ }^{31} 3436-40$ The association of lower fitness levels with higher whole-body fat, lean mass, and fat-free mass is plausible as these are surrogate measures of obesity. Although the latter findings may be surprising, this may simply point to the facts that many other factors affect fitness including genetic factors. ${ }^{41}$ Similarly, the association of low HDL cholesterol with low fitness among men is consistent with a prior report from the general population. ${ }^{34}$

We found that suboptimal fitness is highly common among diabetic individuals free of CVD. This points to an intrinsically impaired exercise response in type 2 diabetes, which can be explained by a number of potential mechanisms. The abnormally slow microvascular blood flow may result in impaired oxygen delivery to the skeletal muscles in response to exercise, ${ }^{101617}$ leading to a higher dependence on oxygen extraction by these muscles in people with type 2 diabetes as compared with controls without diabetes. In addition, the phase 2 kinetics of microvascular blood flow has been shown to be significantly longer in people with type 2 diabetes (without known CVD) as compared with healthy controls. ${ }^{10}$ This supports the notion that metabolic feedback regulation during exercise is altered in type 2 diabetes. ${ }^{10} 42$ Furthermore, impairments in the nitric oxide-mediated endothelial function in arteries of people with type 2 diabetes have been described, which results in a decreased steady-state blood flow to the extremities. ${ }^{43}$ A third mechanism is linked to the reduced mitochondrial content and greater mitochondrial dysfunction in individuals with type 2 diabetes compared with healthy individuals. ${ }^{44}$ This might lead to alterations in the oxidative phosphorylation pathway compromising their ability to use oxygen during exercise. The combination of these mechanisms will result in an oxygen deficit with exercise initiation in type 2 diabetes, which ultimately impact the ability or willingness to maintain activity, resulting in reduced functional capacity. ${ }^{10}$ Furthermore, skeletal muscles represent a substantial substrate for physically fit individuals, ${ }^{46}$ hence higher fitness appears protective as it improves cardiometabolic risk factors such as blood pressure or glycemic markers.

Our findings suggest that strategies targeting both CRF and traditional CVD risk factors could improve health outcomes in people with type 2 diabetes. As professional organizations have advocated for the assessment of CRF in addition to other risk factors, ${ }^{1}$ our study provides data that would help the prioritization of such an assessment of fitness among people 
A 45

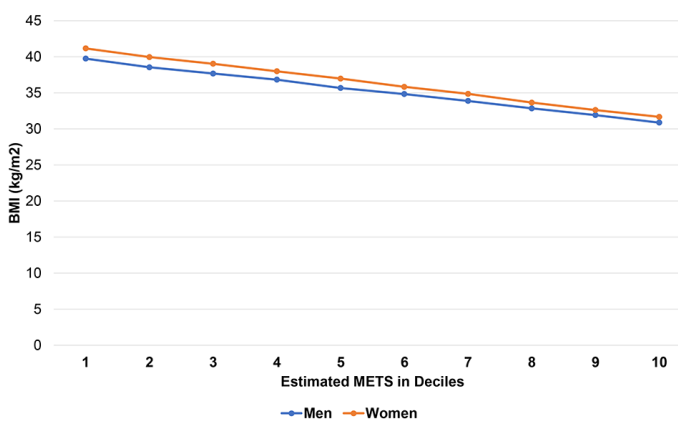

C

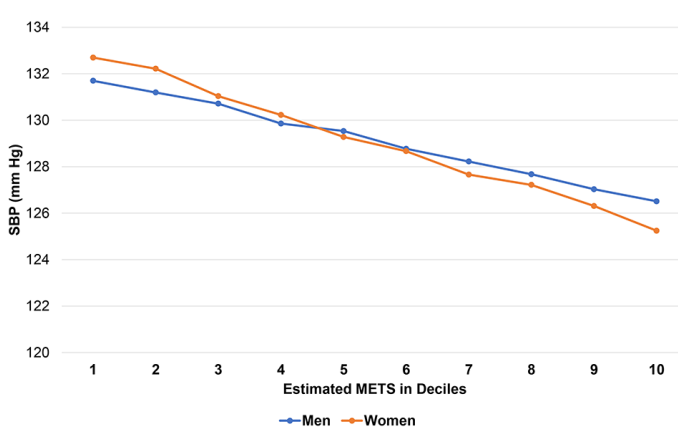

E

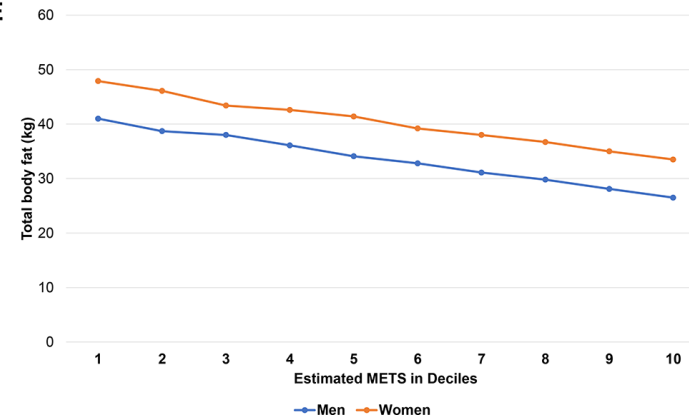

B 140

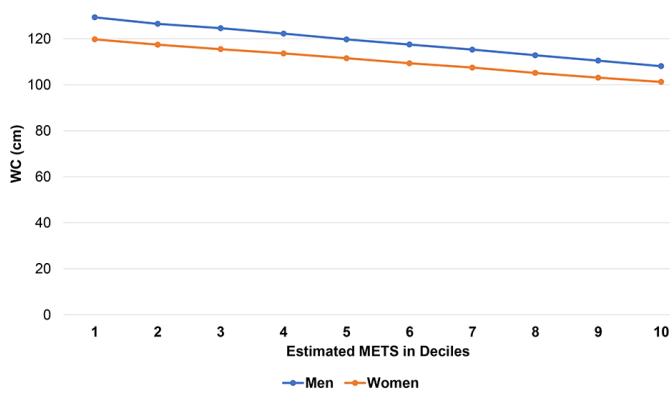

$\rightarrow \rightarrow$ Men $\rightarrow$-Women

D

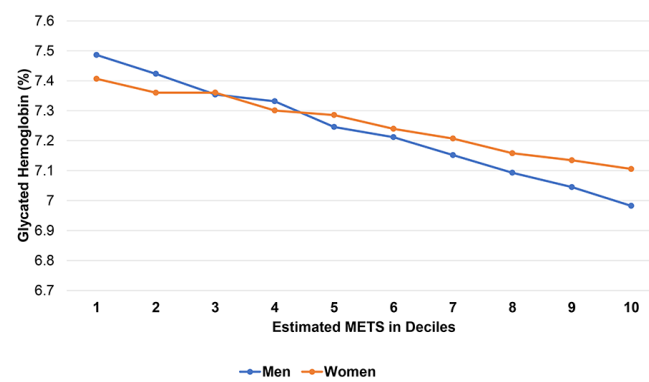

F 8

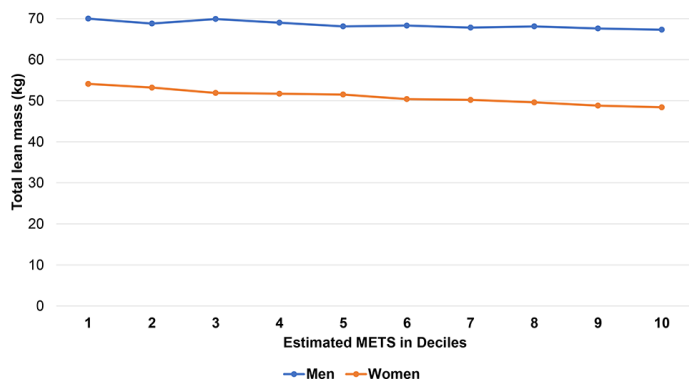

Figure 2 Adjusted means of selected correlates by deciles of fitness and sex among adults with type 2 diabetes in the Look AHEAD study. Means are adjusted for age and race. For fitness decile, 1=low and 10=high. AHEAD indicates Action for Health in Diabetes; BMI, body mass index; MET, metabolic equivalent; SBP, systolic blood pressure; WC, waist circumference.

with type 2 diabetes. Given the rapidly evolving digital healthcare ecosystem with the availability of wearable fitness trackers, the role of these new technologies to assess and monitor fitness levels and its integration in routine clinical practice for possible risk estimation can be explored, especially among people with type 2 diabetes. ${ }^{47}$

Our study has some limitations that should be acknowledged. Its cross-sectional nature limits our ability to establish temporality and thus make any causal inference. This is compounded by the possibility of a bidirectional associations. For example, there could be a bidirectional association between CRF and hypertension or obesity. Fitness and relevant covariates were assessed at a single examination; single-occasion measurements are prone to regression dilution bias, and we may have underestimated the true strength of the associations. In our study, participants had to meet at least 4 METs of fitness to be included, hence these participants were most probably healthier than the general population of people with type 2 diabetes, which limits the generalizability of our findings.

Not with standing the aforementioned limitations, this study has several strengths. First, our study is an attempt to characterize CRF in a large sample of individuals with type 2 diabetes free of CVD, and thus assesses the intrinsic influence of diabetes on CRF. Second, fitness was estimated using objective, maximal treadmill testing; prior studies have used submaximal testing, ${ }^{31}{ }^{34}$ which is inferior to maximal testing for fitness estimation. ${ }^{20}$ Third, relevant covariates including caloric intake, physical activity, and body fat composition were assessed using standardized methods. 


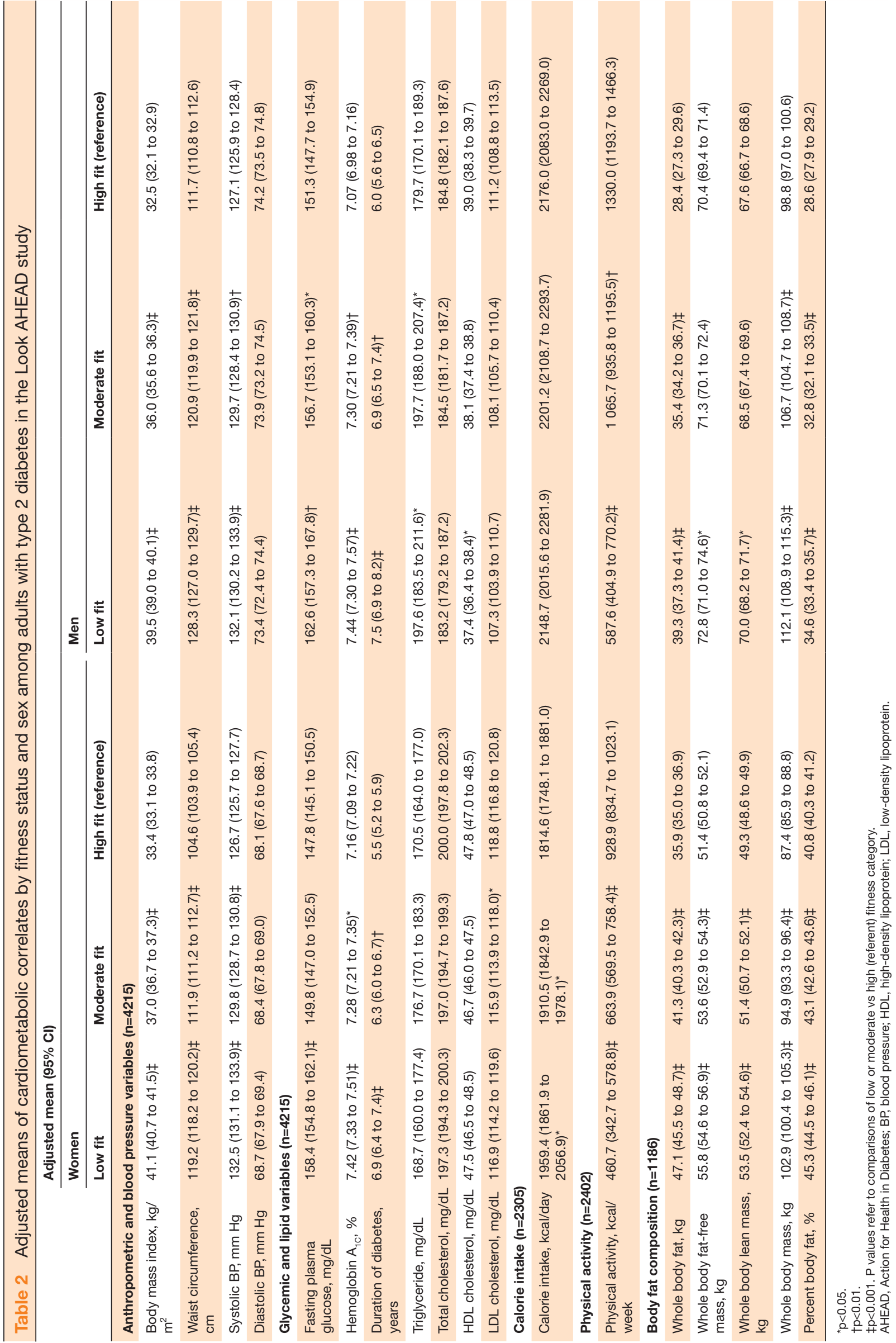


Table 3 Adjusted odds of selected correlates by sex among participants with low (vs moderate or high) fitness status in the Look AHEAD study

\begin{tabular}{|c|c|c|c|c|}
\hline \multirow[b]{2}{*}{ Correlate } & \multicolumn{2}{|l|}{ Women } & \multicolumn{2}{|l|}{ Men } \\
\hline & OR $(95 \% \mathrm{Cl})$ & $P$ value & OR $(95 \% \mathrm{Cl})$ & $P$ value \\
\hline Obesity* & 3.86 (2.55 to 5.84$)$ & $<0.001$ & 3.19 (1.95 to 5.20$)$ & $<0.001$ \\
\hline Abdominal obesity & 2.28 (1.08 to 4.79$)$ & 0.030 & 3.99 (2.00 to 7.96$)$ & $<0.001$ \\
\hline Hypertension & 1.44 (1.02 to 2.05$)$ & 0.040 & 1.74 (1.09 to 2.77 ) & 0.021 \\
\hline Hypercholesterolemia & $1.10(0.89$ to 1.38$)$ & 0.375 & 1.14 (0.84 to 1.53$)$ & 0.402 \\
\hline Low HDL cholesterol & 0.87 (0.71 to 1.08$)$ & 0.209 & 1.02 (0.71 to 1.45$)$ & 0.927 \\
\hline Hypertriglyceridemia & 0.77 (0.60 to 0.97$)$ & 0.028 & 1.10 (0.79 to 1.53$)$ & 0.589 \\
\hline Metabolic syndrome & 2.25 (1.35 to 3.76$)$ & 0.002 & 5.52 (2.51 to 12.14$)$ & $<0.001$ \\
\hline Current smoking & $2.02(1.25$ to 3.28$)$ & 0.004 & 1.47 (0.75 to 2.86$)$ & 0.260 \\
\hline Alcohol drinking & 0.84 (0.65 to 1.08$)$ & 0.177 & 0.80 (0.61 to 1.05$)$ & 0.111 \\
\hline Beta-blocker use & $1.33(1.03$ to 1.73$)$ & 0.029 & 1.22 (0.86 to 1.73$)$ & 0.267 \\
\hline Use of ACEI or ARB & 1.07 (0.86 to 1.32$)$ & 0.543 & 1.86 (1.39 to 2.50$)$ & $<0.001$ \\
\hline
\end{tabular}

Models include age, race, BMI, total-to-HDL cholesterol ratio, $\mathrm{HbA}_{1 \mathrm{C}}$, alcohol drinking, current smoking, and $\mathrm{HTN}$; excluding total-to-HDL cholesterol ratio for hypercholesterolemia and low-HDL cholesterol outcomes; $\mathrm{BMI}, \mathrm{HbA}_{1 \mathrm{C}}$, and $\mathrm{HTN}$ for the metabolic syndrome outcome; HTN for beta-blocker use or ACEI/ARB use outcomes; and BMI for obesity or abdominal obesity outcomes.

Abdominal obesity was defined as waist circumference $\geq 102 \mathrm{~cm}$ for men or $\geq 88 \mathrm{~cm}$ for women.

Hypercholesterolemia was defined as low-density lipoprotein cholesterol of $130 \mathrm{mg} / \mathrm{dL}$ or greater and/or the use of cholesterol-lowering medications.

Hypertension was defined as blood pressure $\geq 130 / 80 \mathrm{~mm} \mathrm{Hg}$ and/or the use of antihypertensive medication.

Low HDL cholesterol was defined as HDL cholesterol $<40 \mathrm{mg} / \mathrm{dL}$ for men or $<50 \mathrm{mg} / \mathrm{dL}$ for women.

Metabolic syndrome was defined based on the National Cholesterol Education Program Adult Treatment Panel III guidelines.

${ }^{*}$ Reference group was overweight (body mass index $\left(\mathrm{BMl}, \mathrm{kg} / \mathrm{m}^{2}\right.$ ) of 25 or greater and less than 30 ). Obesity was defined as $\mathrm{BMI}$ of $30 \mathrm{~kg} / \mathrm{m}^{2}$ or greater.

ACEI, ACE inhibitor; AHEAD, Action for Health in Diabetes; ARB, angiotensin receptor blocker; BMI, body mass index; $\mathrm{HbA}_{1 \mathrm{C}}$, hemoglobin $A_{1 C} ; H D L$, high-density lipoprotein; HTN, hypertension.

In summary, in a community-based sample of men and women with type 2 diabetes, we showed that cardiorespiratory fitness was significantly and associated with a better profile of CVD risk factors. These findings underscore public health recommendations for improving cardiorespiratory fitness among adults with type 2 diabetes, in order to reduce the morbidity and mortality.

Acknowledgements The authors wish to thank the staff and participants of the Look AHEAD study for their valuable contributions.

Contributors ADK performed the statistical analyses, interpreted the results, participated in the discussion, wrote the first draft of the manuscript, revised the manuscript, and approved the final version. DDA, PS, SE, and RSA interpreted the results, participated in the discussion, revised the manuscript, and approved the final version. JBE-T conceived the idea for the study, designed the study, interpreted the results, participated in the discussion, revised the manuscript, and approved the final version. JBE-T is the guarantor of this work and, as such, had full access to all the data in the study and takes responsibility for the integrity of the data and the accuracy of the data analysis.

Funding National Heart, Lung, and Blood Institute (Grant no. K23 HL153774).

Competing interests None declared.

Patient consent for publication Not applicable.

Ethics approval Each participant provided an informed consent, and the research protocol was approved by the Institutional Review Board at each participating center.

Provenance and peer review Not commissioned; externally peer reviewed.

Data availability statement Data may be obtained from a third party and are not publicly available. The data used for the analyses are publicly available through the NHLBI Biorepository (BioLINCC).
Author note (1) The Look AHEAD study was conducted by the Look AHEAD Investigators and supported by the National Institute of Diabetes and Digestive and Kidney Diseases (NIDDK). The data from the Look AHEAD reported here were supplied by the NIDDK Central Repositories. This manuscript was not prepared in collaboration with Investigators of the Look AHEAD study and does not necessarily reflect the opinions or views of the Look Ahead Study, the NIDDK Central Repositories, or the NIDDK. (2) Look AHEAD was conducted by the Look AHEAD Research Group and supported by the National Institute of Diabetes and Digestive and Kidney Diseases (NIDDK); the National Heart, Lung, and Blood Institute (NHLBI); the National Institute of Nursing Research (NINR); the National Institute of Minority Health and Health Disparities (NIMHD); the Office of Research on Women's Health (ORWH); and the Centers for Disease Control and Prevention (CDC). The data (and samples) from Look AHEAD were supplied by the NIDDK Central Repositories. This manuscript was not prepared under the auspices of the Look AHEAD and does not represent analyses or conclusions of the Look AHEAD Research Group, the NIDDK Central Repositories, or the $\mathrm{NIH}$.

Open access This is an open access article distributed in accordance with the Creative Commons Attribution Non Commercial (CC BY-NC 4.0) license, which permits others to distribute, remix, adapt, build upon this work non-commercially, and license their derivative works on different terms, provided the original work is properly cited, appropriate credit is given, any changes made indicated, and the use is non-commercial. See: http://creativecommons.org/licenses/by-nc/4.0/.

ORCID IDs

Arnaud D Kaze http://orcid.org/0000-0002-5470-8296

Dayawa Da Agoons http://orcid.org/0000-0002-7547-8282

Justin B Echouffo-Tcheugui http://orcid.org/0000-0002-8460-1617

\section{REFERENCES}

1 Ross R, Blair SN, Arena R, et al. Importance of assessing cardiorespiratory fitness in clinical practice: a case for fitness as a clinical vital sign: a scientific statement from the American Heart Association. Circulation 2016;134:e653-99. 
2 Kaminsky LA, Arena R, Beckie TM, et al. The importance of cardiorespiratory fitness in the United States: the need for a national registry: a policy statement from the American Heart Association. Circulation 2013;127:652-62.

3 Guazzi M, Arena R, Halle M, et al. 2016 Focused update: clinical recommendations for cardiopulmonary exercise testing data assessment in specific patient populations. Eur Heart $J$ 2018;39:1144-61.

4 Laukkanen JA, Kurl S, Salonen R, et al. The predictive value of cardiorespiratory fitness for cardiovascular events in men with various risk profiles: a prospective population-based cohort study. Eur Heart J 2004;25:1428-37.

5 Blair SN, Kohl HW, Paffenbarger RS, et al. Physical fitness and all-cause mortality. a prospective study of healthy men and women. JAMA 1989;262:2395-401.

6 Sawada SS, Lee I-M, Naito H, et al. Cardiorespiratory fitness, body mass index, and cancer mortality: a cohort study of Japanese men. BMC Public Health 2014;14:1012.

7 Cheng YJ, Kanaya AM, Araneta MRG, et al. Prevalence of diabetes by race and ethnicity in the United States, 2011-2016. JAMA 2019;322:2389-98.

8 Virani SS, Alonso A, Benjamin EJ, et al. Heart disease and stroke statistics-2020 update: a report from the American Heart Association. Circulation 2020;141:e139-596.

9 Flegal KM, Kruszon-Moran D, Carroll MD, et al. Trends in obesity among adults in the United States, 2005 to 2014. JAMA 2016;315:2284-91.

10 Bauer TA, Reusch JEB, Levi M, et al. Skeletal muscle deoxygenation after the onset of moderate exercise suggests slowed microvascular blood flow kinetics in type 2 diabetes. Diabetes Care 2007:30:2880-5.

11 Brandenburg SL, Reusch JE, Bauer TA, et al. Effects of exercise training on oxygen uptake kinetic responses in women with type 2 diabetes. Diabetes Care 1999;22:1640-6.

12 Regensteiner JG, Bauer TA, Reusch JEB, et al. Cardiac dysfunction during exercise in uncomplicated type 2 diabetes. Med Sci Sports Exerc 2009;41:977-84.

13 Kjaer M, Hollenbeck CB, Frey-Hewitt B, et al. Glucoregulation and hormonal responses to maximal exercise in non-insulin-dependent diabetes. J Appl Physiol 1990;68:2067-74.

14 Regensteiner JG, Bauer TA, Reusch JE, et al. Abnormal oxygen uptake kinetic responses in women with type II diabetes mellitus. $J$ Appl Physiol 1998;85:310-7.

15 Regensteiner JG, Sippel J, McFarling ET, et al. Effects of noninsulin-dependent diabetes on oxygen consumption during treadmill exercise. Med Sci Sports Exerc 1995;27:661???667-81.

16 Padilla DJ, McDonough P, Behnke BJ, et al. Effects of type II diabetes on muscle microvascular oxygen pressures. Respir Physiol Neurobiol 2007;156:187-95.

17 Padilla DJ, McDonough P, Behnke BJ, et al. Effects of type II diabetes on capillary hemodynamics in skeletal muscle. $A m \mathrm{~J}$ Physiol Heart Circ Physiol 2006;291:H2439-44.

18 Ryan DH, Espeland MA, Foster GD, et al. Look AHEAD (Action for Health in Diabetes): design and methods for a clinical trial of weight loss for the prevention of cardiovascular disease in type 2 diabetes. Control Clin Trials 2003;24:610-28.

19 Jakicic JM, Jaramillo SA, Balasubramanyam A, et al. Effect of a lifestyle intervention on change in cardiorespiratory fitness in adults with type 2 diabetes: results from the Look AHEAD study. Int $J$ Obes 2009;33:305-16.

20 ACSM. Medicine AC of S. In: ACSM's guidelines for exercise testing and prescription. Lippincott Williams \& Wilkins, 2013.

21 Church TS, LaMonte MJ, Barlow CE, et al. Cardiorespiratory fitness and body mass index as predictors of cardiovascular disease mortality among men with diabetes. Arch Intern Med 2005;165:2114-20.

22 Mayer-Davis EJ, Vitolins MZ, Carmichael SL, et al. Validity and reproducibility of a food frequency interview in a multi-cultural epidemiology study. Ann Epidemiol 1999;9:314-24.

23 Paffenbarger RS, Wing AL, Hyde RT. Physical activity as an index of heart attack risk in college alumni. Am J Epidemiol 1978;108:161-75.

24 Pownall HJ, Bray GA, Wagenknecht LE, et al. Changes in body composition over 8 years in a randomized trial of a lifestyle intervention: the look AHEAD study. Obesity 2015;23:565-72.

25 Galgani JE, Smith SR, Ravussin E. Assessment of EchoMRI-AH versus dual-energy $\mathrm{X}$-ray absorptiometry to measure human body composition. Int J Obes 2011;35:1241-6.
26 Schoeller DA, Tylavsky FA, Baer DJ, et al. QDR 4500A dual-energy $\mathrm{X}$-ray absorptiometer underestimates fat mass in comparison with criterion methods in adults. Am J Clin Nutr 2005;81:1018-25.

27 Friedewald WT, Levy RI, Fredrickson DS. Estimation of the concentration of low-density lipoprotein cholesterol in plasma, without use of the preparative ultracentrifuge. Clin Chem 1972;18:499-502.

28 Jensen MD, Ryan DH, Apovian CM, et al. 2013 AHA/ACC/TOS guideline for the management of overweight and obesity in adults: a report of the American College of Cardiology/American Heart Association Task Force on Practice Guidelines and the Obesity Society. Circulation 2014;129:S102-38.

29 Whelton PK, Carey RM, Aronow WS, et al. 2017 ACC/AHA/AAPA/ ABC/ACPM/AGS/APhA/ASH/ASPC/NMA/PCNA guideline for the prevention, detection, evaluation, and management of high blood pressure in adults: executive summary: a report of the American College of Cardiology/American Heart Association Task force on clinical practice guidelines. Hypertension 2018;71:1269-324.

30 Grundy SM, Brewer HB, Cleeman JI, et al. Definition of metabolic syndrome: report of the National Heart, Lung, and Blood Institute/ American Heart Association conference on scientific issues related to definition. Circulation 2004:109:433-8.

31 Wang C-Y, Haskell WL, Farrell SW, et al. Cardiorespiratory fitness levels among US adults 20-49 years of age: findings from the 1999-2004 National Health and Nutrition Examination Survey. Am J Epidemiol 2010;171:426-35.

32 Curtis JM, Horton ES, Bahnson J, et al. Prevalence and predictors of abnormal cardiovascular responses to exercise testing among individuals with type 2 diabetes: the Look AHEAD (Action for Health in Diabetes) study. Diabetes Care 2010;33:901-7.

33 Ribisl PM, Lang W, Jaramillo SA, et al. Exercise capacity and cardiovascular/metabolic characteristics of overweight and obese individuals with type 2 diabetes: the Look AHEAD clinical trial. Diabetes Care 2007;30:2679-84.

34 Carnethon MR, Gulati M, Greenland P. Prevalence and cardiovascular disease correlates of low cardiorespiratory fitness in adolescents and adults. JAMA 2005;294:2981-8.

35 Shrank WH, Patrick AR, Brookhart MA. Healthy user and related biases in observational studies of preventive interventions: a primer for physicians. J Gen Intern Med 2011;26:546-50.

36 LaMonte MJ, Eisenman PA, Adams TD, et al. Cardiorespiratory fitness and coronary heart disease risk factors: the LDS Hospital Fitness Institute cohort. Circulation 2000;102:1623-8.

37 Gibbons LW, Blair SN, Cooper KH, et al. Association between coronary heart disease risk factors and physical fitness in healthy adult women. Circulation 1983;67:977-83.

38 Cooper KH, Pollock ML, Martin RP, et al. Physical fitness levels vs selected coronary risk factors. a cross-sectional study. JAMA 1976;236:166-9.

39 Whaley MH, Kampert JB, Kohl HW, et al. Physical fitness and clustering of risk factors associated with the metabolic syndrome. Med Sci Sports Exerc 1999;31:287-93.

40 Suzuki I, Yamada H, Sugiura T, et al. Cardiovascular fitness, physical activity and selected coronary heart disease risk factors in adults. $J$ Sports Med Phys Fitness 1998;38:149-57.

41 Teran-Garcia M, Rankinen T, Bouchard C. Genes, exercise, growth, and the sedentary, obese child. J Appl Physiol 2008;105:988-1001.

42 Sachidanandam K, Harris A, Hutchinson J, et al. Microvascular versus macrovascular dysfunction in type 2 diabetes: differences in contractile responses to endothelin-1. Exp Biol Med 2006;231:1016-21.

43 Williams SB, Cusco JA, Roddy MA, et al. Impaired nitric oxidemediated vasodilation in patients with non-insulin-dependent diabetes mellitus. J Am Coll Cardiol 1996;27:567-74.

44 Ritov VB, Menshikova EV, He J, et al. Deficiency of subsarcolemmal mitochondria in obesity and type 2 diabetes. Diabetes 2005:54:8-14.

45 Kelley DE, He J, Menshikova EV, et al. Dysfunction of mitochondria in human skeletal muscle in type 2 diabetes. Diabetes 2002;51:2944-50.

46 Reusch JEB, Bridenstine M, Regensteiner JG. Type 2 diabetes mellitus and exercise impairment. Rev Endocr Metab Disord 2013;14:77-86

47 Bayoumy K, Gaber M, Elshafeey A, et al. Smart wearable devices in cardiovascular care: where we are and how to move forward. Nat Rev Cardiol 2021;18:581-99. 